\title{
The use of misoprostol for cervical priming prior to hysteroscopy: a systematic review and analysis
}

This article was published in the following Dove Press journal:

Drug Design, Development and Therapy

6 September 2016

Number of times this article has been viewed

Ying Hua

Wenwen Zhang

Xiaoli Hu

Ansu Yang

Xueqiong Zhu

Department of Obstetrics and Gynecology, The Second Affiliated Hospital of Wenzhou Medical University, Wenzhou, People's Republic of China
Correspondence: Xueqiong Zhu

Department of Obstetrics and Gynecology, The Second Affiliated Hospital of Wenzhou Medical University, No 109 Xueyuan Xi Road, Wenzhou, Zhejiang, 325027, People's Republic of China

Tel +8657788002796

Fax +8657788832693

Email zjwzzxq@।63.com

\begin{abstract}
The effects of misoprostol use on cervical priming prior to hysteroscopy have been controversial. Therefore, a systematic literature review and meta-analysis of studies were conducted to assess the effect of misoprostol on cervical priming prior to hysteroscopy. All studies published before July 2014 with data related to the use of misoprostol for cervical priming compared with placebo or no medication prior to hysteroscopy, were identified. Twenty-five randomized controlled trials involving 2,203 females were systematically analyzed. The results showed that, compared with placebo or no medication, the use of misoprostol prior to hysteroscopy led to a significant relief of the need for cervical dilatation, resulted in a significantly greater cervical width, had fewer hysteroscopy complications, and mild and insignificant side effects. Subgroup analyses revealed that the regimen of 200 or $400 \mu \mathrm{g}$ vaginal misoprostol may be a simple and effective method for cervical priming, especially prior to operative hysteroscopy.

Keywords: misoprostol, hysteroscopy, cervical priming, cervical dilatation, complications, systematic review
\end{abstract}

\section{Introduction}

Hysteroscopy is a minimally invasive approach for observing the uterine cavity for a variety of gynecological problems, and has become a valuable diagnostic and therapeutic procedure. ${ }^{1,2}$ Also, hysteroscopy is potentially useful for female sterilization and offers promise as an investigative tool for studying the intratubal milieu. ${ }^{3}$ However, many patients undergoing the procedure are at risk for cervical dilatation complications, such as cervical laceration, uterine perforation, and creation of false passages. ${ }^{4}$ Fortunately, the incidence of these complications may be reduced if the cervix is ripened beforehand.

Misoprostol, a prostaglandin E1 analog, which was initially used for the treatment of peptic ulcers, has been widely applied in obstetrics and gynecology because of its ripening effect on cervix during the induction of abortion or labor. ${ }^{5,6}$ The primary advantages of the drug include its thermostability, low cost, and the ease of administration. ${ }^{7}$ Moreover, misoprostol is available in many formulations: tablets or gelcaps, at doses of $200,400,800$, and $1,000 \mu \mathrm{g}$, and can be administered by mouth or sublingually, as well as via the rectal or vaginal route. ${ }^{8-10}$ Because of its effect on cervical ripening in pregnant females, misoprostol has also been used for cervical priming prior to hysteroscopy by surgeons. While numerous studies indicated the efficacy of misoprostol for achieving cervical dilatation in patients undergoing hysteroscopy, ${ }^{10-15}$ some reports concluded that the use of misoprostol before hysteroscopy did not facilitate cervical dilatation..$^{8,9,16-18}$ The discrepancy may be due to small sample sizes, differences in the route of administration of misoprostol, the types of 
hysteroscopy (operative or diagnostic hysteroscopy), and/or different populations under study.

To more systematically evaluate the efficacy and safety of misoprostol for cervical priming prior to hysteroscopy, we conducted a meta-analysis on randomized controlled trials (RCTs) comparing misoprostol versus placebo or no medication before diagnostic or operative hysteroscopy in females receiving hysteroscopy. In addition, we hope that such analyses would help in determining the optimal dose and route of administration for the application of misoprostol in hysteroscopy.

\section{Methods}

\section{Search strategy}

We searched (published up to July 2014) the three most popular databases - MEDLINE (via PubMed), EMBASE (via embase.com), and Cochrane - for articles in any language. The search strategy used the terms "hysteroscopy" AND "misoprostol". In addition, the references of the relevant articles and previous systematic reviews were checked to identify potentially eligible trials.

\section{Selection criteria}

We included RCTs for cervical priming using misoprostol prior to diagnostic or operative hysteroscopy in females regardless of age, parity, or other characteristics. The intervention in the trials was the use of misoprostol compared with placebo or no medication before hysteroscopy. No restriction was placed on dose, route, or timing of misoprostol administration. We excluded studies without a placebo or no medication group, as well as those comparing misoprostol to another method (laminaria tents or dinoprostone). Nonrandomized trials such as case-control studies were also excluded.

\section{Data extraction and quality assessment}

Two reviewers, YH and WWZ, independently extracted the data that were retrieved from the search. The results were then compared and disagreements were resolved by discussion. If the two primary reviews could not reach a consensus the third reviewer (XLH) was be consulted. Information of the authorship, publication year, patient demographics, type of intervention, and outcomes were extracted. To assess the validity of the included trials, two investigators ( $\mathrm{YH}$ and WWZ) independently examined the study quality using the Cochrane Handbook for Systematic Reviews of Interventions with respect to the generation of random sequences, allocation concealment, blinding, incomplete outcome data, and selective reporting. ${ }^{19}$ The risk of publication bias was assessed using funnel plots.

\section{Outcomes}

The outcomes of interest for this article included the following variables: number of females who required cervical dilatation, cervical width at the start of hysteroscopy, hysteroscopy complications such as cervical tears and uterine perforation, and the incidence of misoprostol side effects such as abdominal pain, nausea, diarrhea, genital bleeding, and fever.

\section{Data synthesis}

Statistical analyses were performed with the use of Review Manager (RevMan), Version 5.1 (The Nordic Cochrane Centre, the Cochrane Collaboration, Copenhagen, Denmark). To calculate the risk ratio (RR) for dichotomous data and the mean differences (MD) for continuous data with 95\% confidence intervals (CIs), the fixed effects model was used. Statistical significance was set at a $P$-value of $<0.05$. We evaluated statistical heterogeneity by employing $P$-values, chi-square, and $I^{2}$ tests. ${ }^{20}$ If significant heterogeneity was found $(P \leq 0.10$, $I^{2}>50 \%$ ), a random effects model was applied to limit the effects of heterogeneity. A subgroup analysis was also performed to reveal the possible reasons for the heterogeneity.

\section{Results \\ Description of studies}

A total of 2,203 females requiring hysteroscopy from 25 RCTs were included in this meta-analysis. A flow diagram for the literature search is presented in Figure 1A.

We identified 25 randomized studies comparing misoprostol versus placebo or no medication prior to hysteroscopy. Table 1 summarizes the characteristics of these studies, which include seven studies of operative hysteroscopy, ${ }^{8-10,13,14,21,22}$ 13 studies of diagnostic hysteroscopy, ${ }^{16-18,23-32}$ and five studies on both diagnostic and operative hysteroscopy. ${ }^{11,12,15,33,34}$ Additionally, the route of misoprostol administration was oral (four studies), vaginal (18 studies), sublingual (four studies), or rectal (one study). Table 1 shows that the dose of misoprostol administration prior to hysteroscopy differed considerably among the available trials and the outcomes.

\section{Quality of trials and assessment of publication bias}

Two investigators independently assessed the risk of bias of the eligible trials by using the Cochrane Handbook for Systematic Reviews of Interventions, ${ }^{19}$ and a consensus was reached after discussion. As demonstrated in Figure 1B, 
A

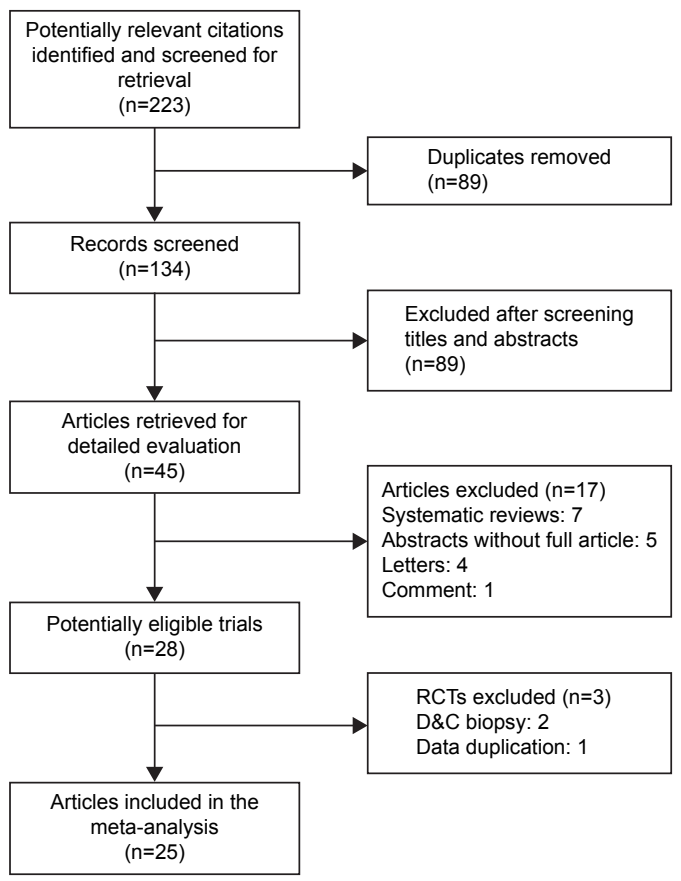

B

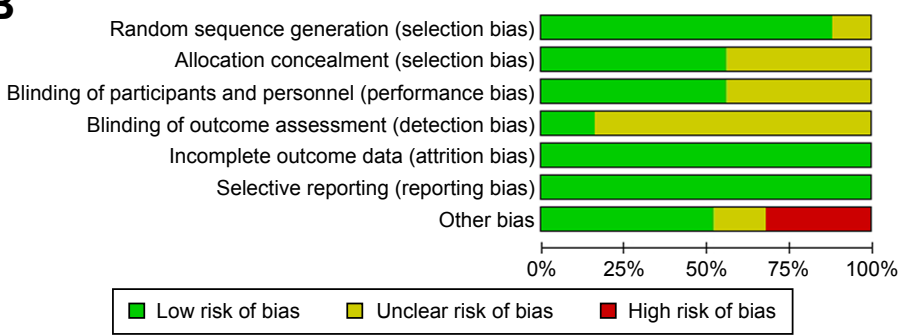

C

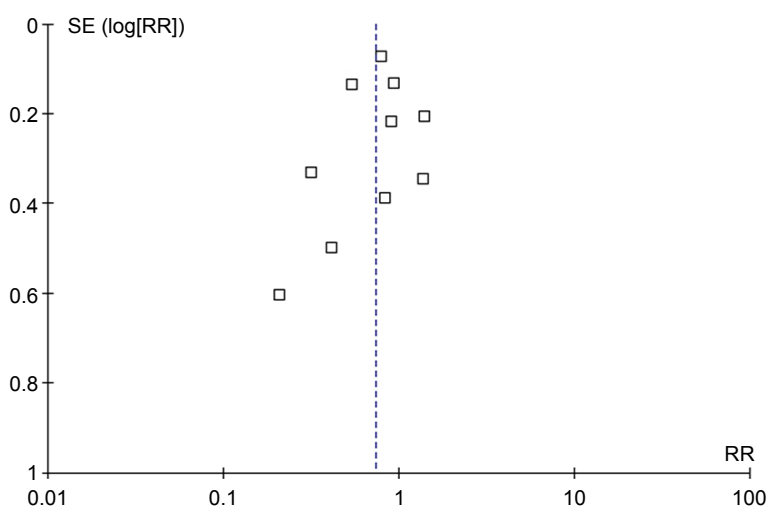

Figure I Flow diagram and quality of the selected study.

Notes: (A) Flow diagram for study selection. (B) Risk of bias assessment. (C) Funnel plot of comparison: need for cervical dilatation.

Abbreviations: D\&C, dilatation and curettage; RCTs, randomized controlled trials; RR, risk ratio; SE, standard error.

most of the included trials had properly randomized their participants and $60 \%$ had adequate randomization allocations. With regard to performance bias, $60 \%$ had adequate blinding. All papers were judged to be free of attrition and reporting biases.

As shown in Figure 1C, the funnel plots appeared to be symmetrical, which indicated that there was no obvious publication bias.

\section{Outcomes}

\section{Need for cervical dilatation}

Data on the need for cervical dilatation before hysteroscopy were reported in ten studies that included a total of 930 females. Due to the high statistical heterogeneity, results were pooled using the random effects model. Compared with placebo or no medication, misoprostol administration prior to hysteroscopy reduced the need for cervical dilatation to a statistically significant degree (RR $0.75 ; 95 \%$ CI $0.58-0.96 ; P=75 \%$ Figure $2 \mathrm{~A}$ ).

By subgroup analysis, when only operative hysteroscopy was examined, the need for cervical dilatation in the misoprostol group was significantly decreased compared to the placebo or no medication groups (RR $0.79 ; 95 \%$ CI $0.69-0.91$ Figure 3A), while the need for cervical dilatation was not significantly decreased before diagnostic hysteroscopy (RR 0.97; 95\% CI 0.80-1.17; $I^{2}=32 \%$ Figure 3B). The need for cervical dilatation after vaginal misoprostol administration was significantly decreased compared to placebo or no medication (RR $0.68 ; 95 \%$ CI $0.51-0.92 ; P^{2}=76 \%$ Figure $2 \mathrm{~B}$ ), while after sublingual (RR $0.81 ; 95 \%$ CI $0.22-3.00 ; I^{2}=84 \%$ Figure 4A) and oral (RR 0.90; 95\% CI 0.59-1.38; Figure 4B) misoprostol administration, the need for cervical dilatation was not significantly decreased.

\section{Cervical width}

Fourteen trials provided data on the MD in the cervical width before the hysteroscopy. Patients receiving misoprostol appeared to have a significantly greater cervical width compared with placebo or no medication (MD $1.34 \mathrm{~mm}$; 95\% CI $0.55-2.14 ; l^{2}=98 \%$ Figure $\left.5 \mathrm{~A}\right)$. The cervical width after vaginal misoprostol administration was significantly greater than that in the placebo or no medication group (MD $1.64 \mathrm{~mm}$; 95\% CI 0.93-2.35; $I^{2}=95 \%$ Figure 5B), but after sublingual (MD $0.40 \mathrm{~mm} ; 95 \% \mathrm{CI}-0.80$ to $1.61 ; l^{2}=98 \%$ Figure $6 \mathrm{~A}$ ) or oral (MD $-0.20 \mathrm{~mm} ; 95 \% \mathrm{CI}-1.31$ to 0.91 ; Figure 6B) misoprostol administration cervical width was not significantly greater. In addition, in the $200 \mu \mathrm{g}$ subgroup (MD $2.20 \mathrm{~mm} ; 95 \%$ CI $1.21-3.19 ; I^{2}=94 \%$ Figure $7 \mathrm{~A}$ ) or the $400 \mu \mathrm{g}$ subgroup (MD $2.20 \mathrm{~mm} ; 95 \% \mathrm{CI} 1.14-3.26 ; I^{2}=92 \%$ Figure 7B), the cervical width was significantly greater than that in the placebo or no medication group, while it was not 


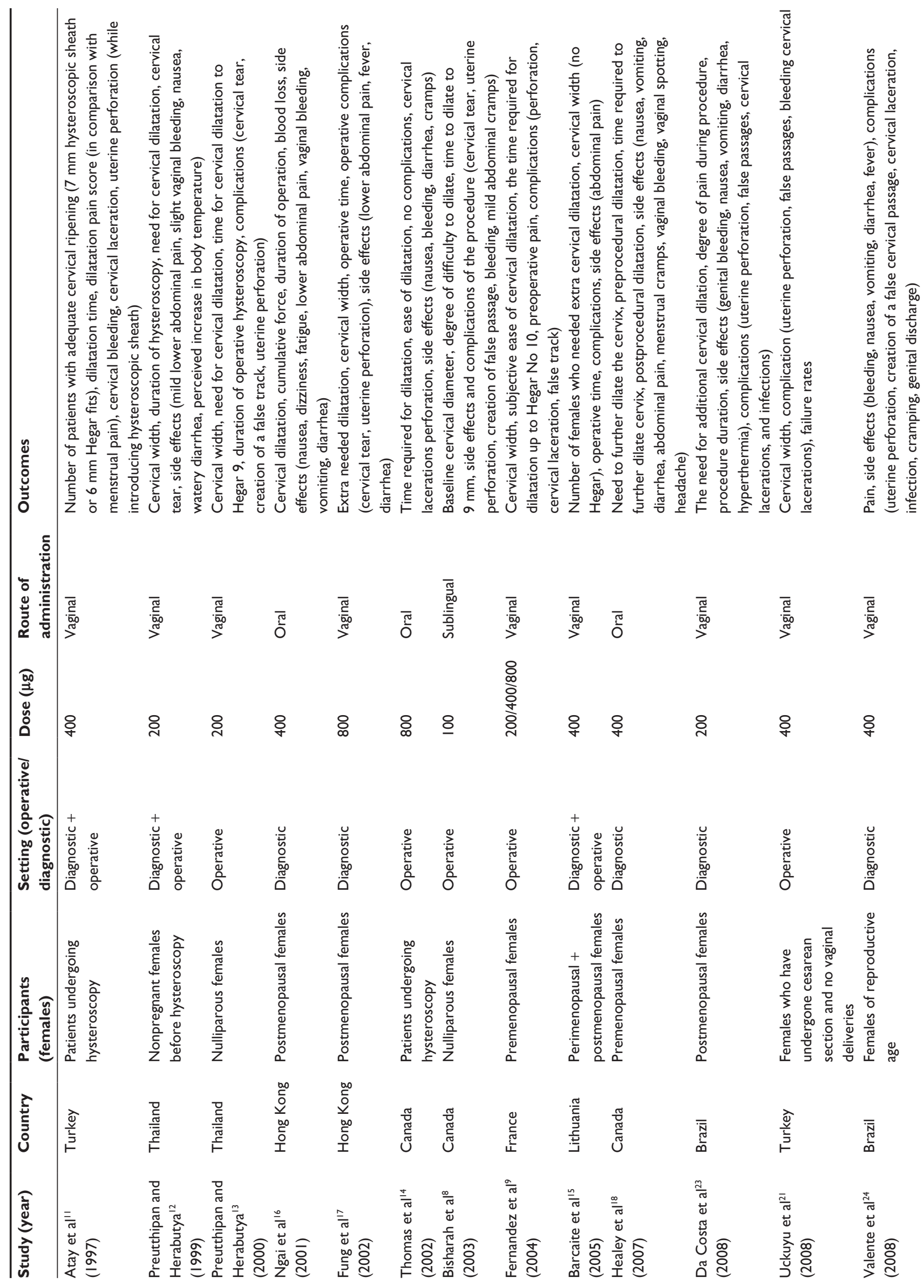



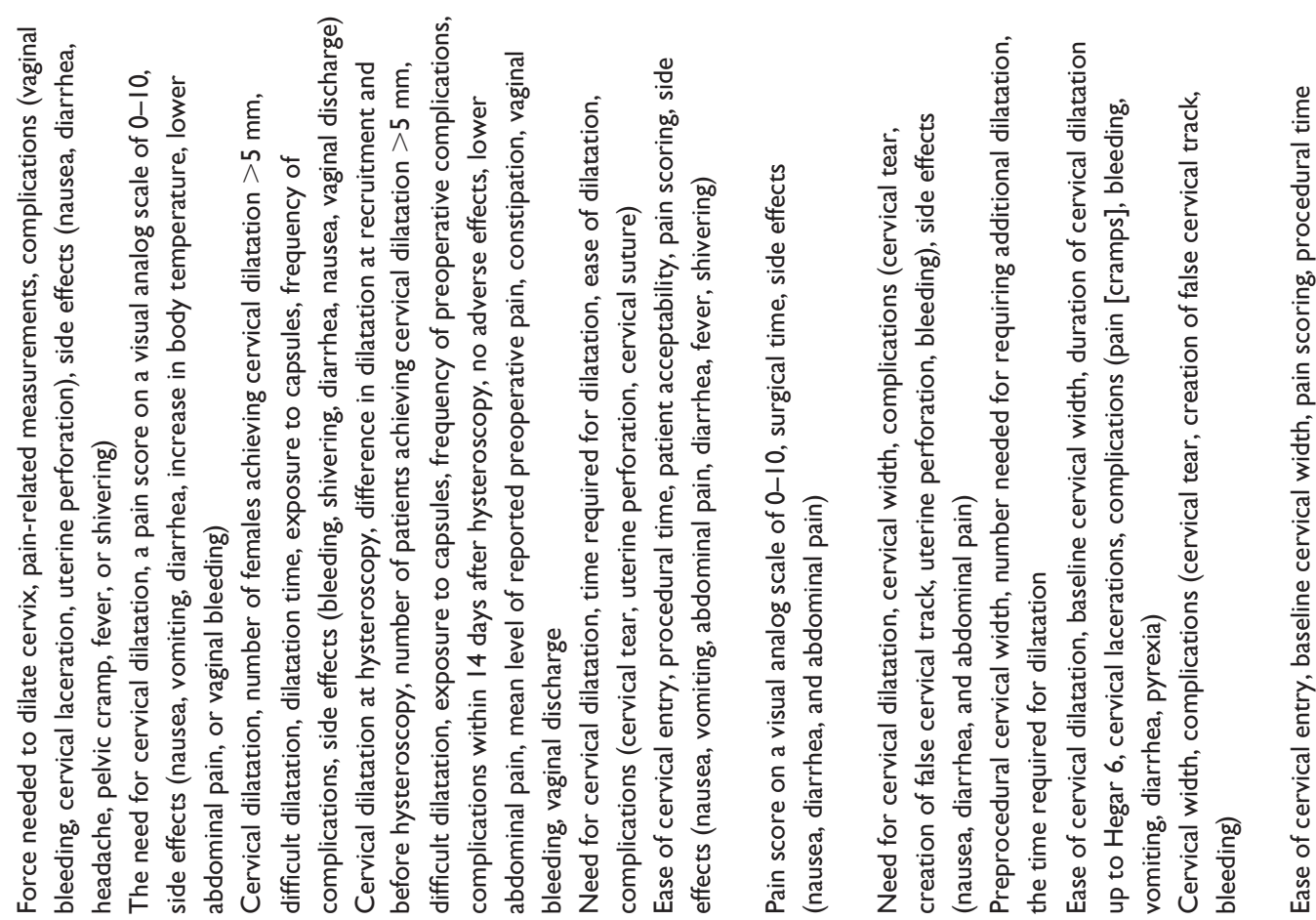

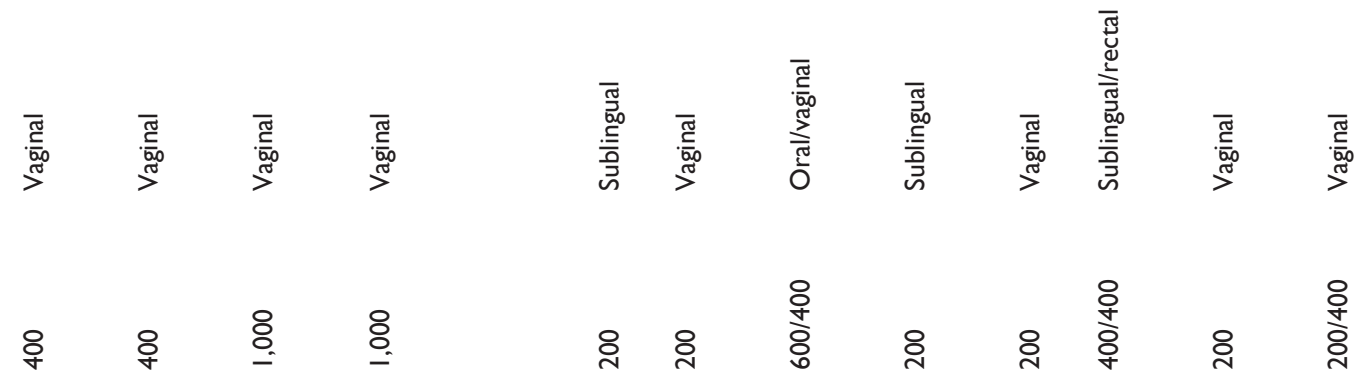
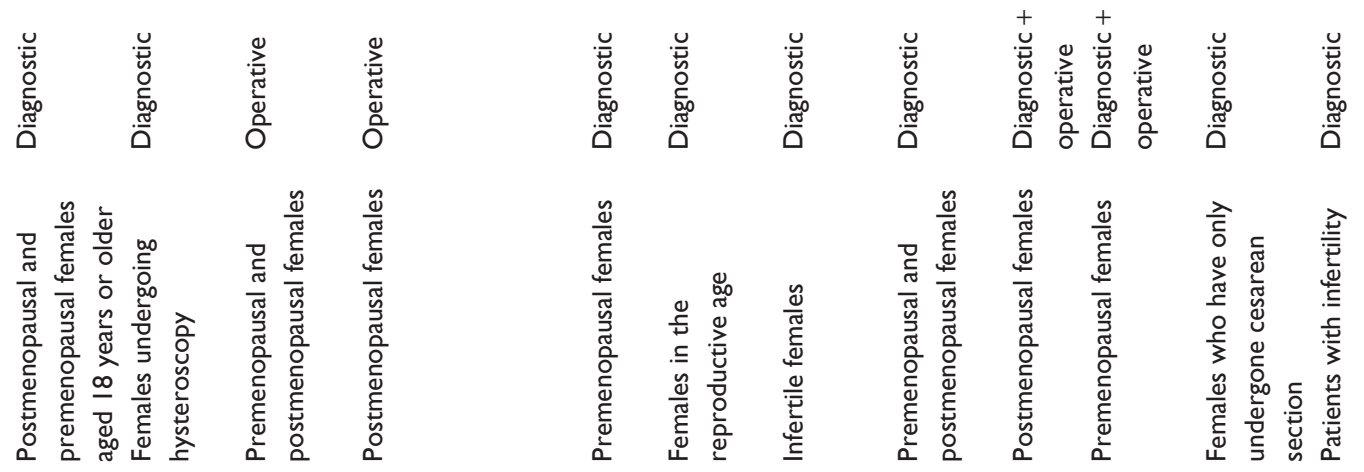

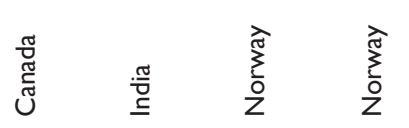

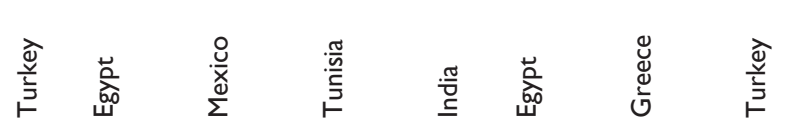

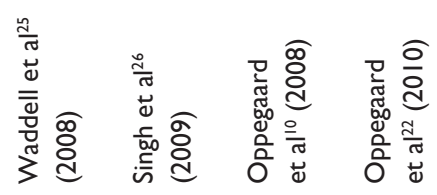

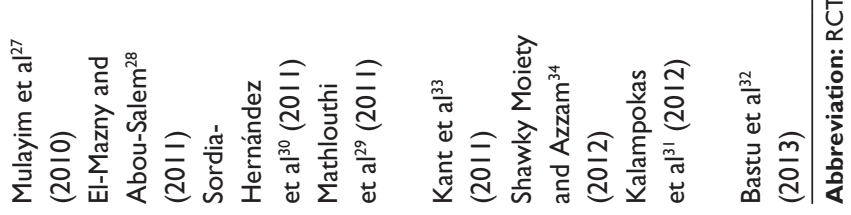




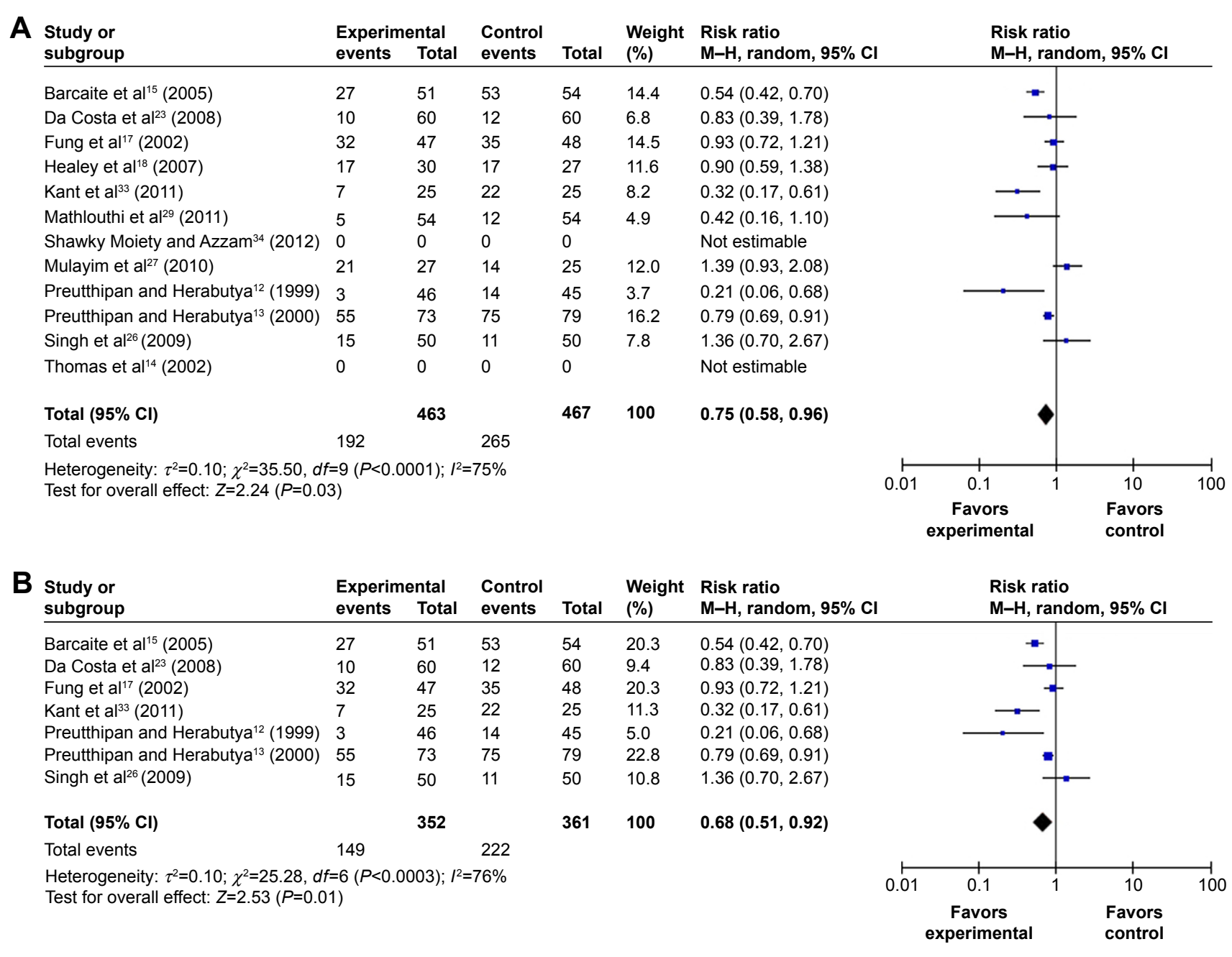

Figure 2 Comparison of the need for cervical dilatation between the misoprostol group and the placebo or no medication group, including both operative and diagnostic hysteroscopy studies.

Notes: (A) Irrespective of the route of misoprostol administration. (B) Vaginal misoprostol administration.

Abbreviations: $\mathrm{Cl}$, confidence interval; $\mathrm{df}$, degrees of freedom; $\mathrm{M}-\mathrm{H}$, Mantel-Haenszel.

in the $800 \mu \mathrm{g}$ subgroup (MD $0.16 \mathrm{~mm} ; 95 \% \mathrm{CI}-0.33$ to 0.66 ; $I^{2}=0 \%$ Figure $8 \mathrm{~A}$ ) or the $1,000 \mu \mathrm{g}$ subgroup (MD $0.60 \mathrm{~mm}$; $95 \% \mathrm{CI}-0.73$ to $1.94 ; I^{2}=76 \%$ Figure $\left.8 \mathrm{~B}\right)$.

\section{Complication of hysteroscopy}

There was no significant difference between the misoprostol group and the placebo or no medication group when assessing the uterine perforation rate. However, the analysis of 14 trials, including 1,358 females, showed that the use of misoprostol prior to hysteroscopy resulted in a statistically significant decrease in the rate of cervical lacerations compared to placebo or no medication. When analyzing false passage, the risk was also significantly lower in the misoprostol group. All effect estimates for the above hysteroscopy complications with 95\% CIs and $P$-values are shown in Table 2.

In addition, compared with placebo or no medication, hysteroscopy complications (cervical lacerations and false passage) after vaginal misoprostol (RR 0.36; 95\% CI, 0.19-0.66; ten trials, 848 patients in Figure 9A; RR 0.37; 95\% CI, 0.16-0.88; six trials, 520 patients in Figure 10A) administration were significantly decreased, but not after sublingual and oral (RR 0.48; 95\% CI, 0.22-1.03; four trials, 381 patients in Figure 9B; RR 0.2; 95\% CI, 0.02-1.66; one trial, 54 patients in Figure 10B) misoprostol administration.

\section{Side effects of misoprostol}

The pooled analysis ruled out that misoprostol side effects such as mild abdominal pain, bleeding, nausea, diarrhea, and fever were significantly more frequent in the misoprostol group compared with placebo or no medication. These side effects were generally minor, transient, and tolerable without the need for further treatment. All the patients were discharged on the day of the procedure. 


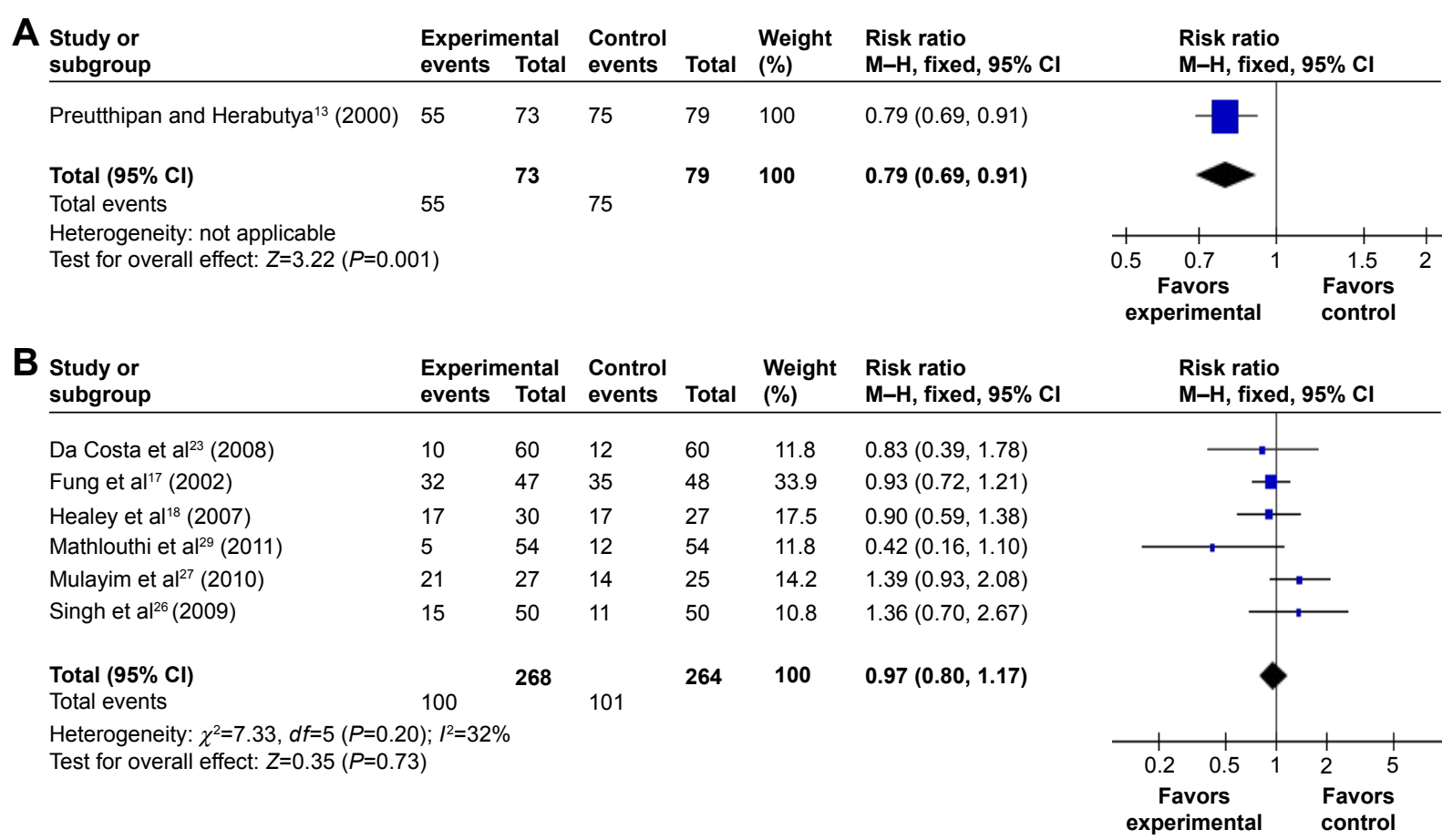

Figure 3 Comparison of the need for cervical dilatation between the misoprostol group and the placebo or no medication group, including vaginal, oral, sublingual administration routes.

Notes: (A) Operative hysteroscopy. (B) Diagnostic hysteroscopy.

Abbreviations: $\mathrm{Cl}$, confidence interval; $\mathrm{df}$, degrees of freedom; $\mathrm{M}-\mathrm{H}$, Mantel-Haenszel.

All effect estimates for misoprostol side effects with 95\% CIs and $P$-values are shown in Table 2.

\section{Discussion}

This meta-analysis indicates that misoprostol prior to hysteroscopy may facilitate cervical dilatation. Misoprostol, when given vaginally, was more effective when compared with oral and sublingual administration. The mean cervical width was significantly larger in the misoprostol group. In addition, hysteroscopy complications such as cervical laceration and false passage were significantly less frequent in the misoprostol group with the exception of uterine perforation.

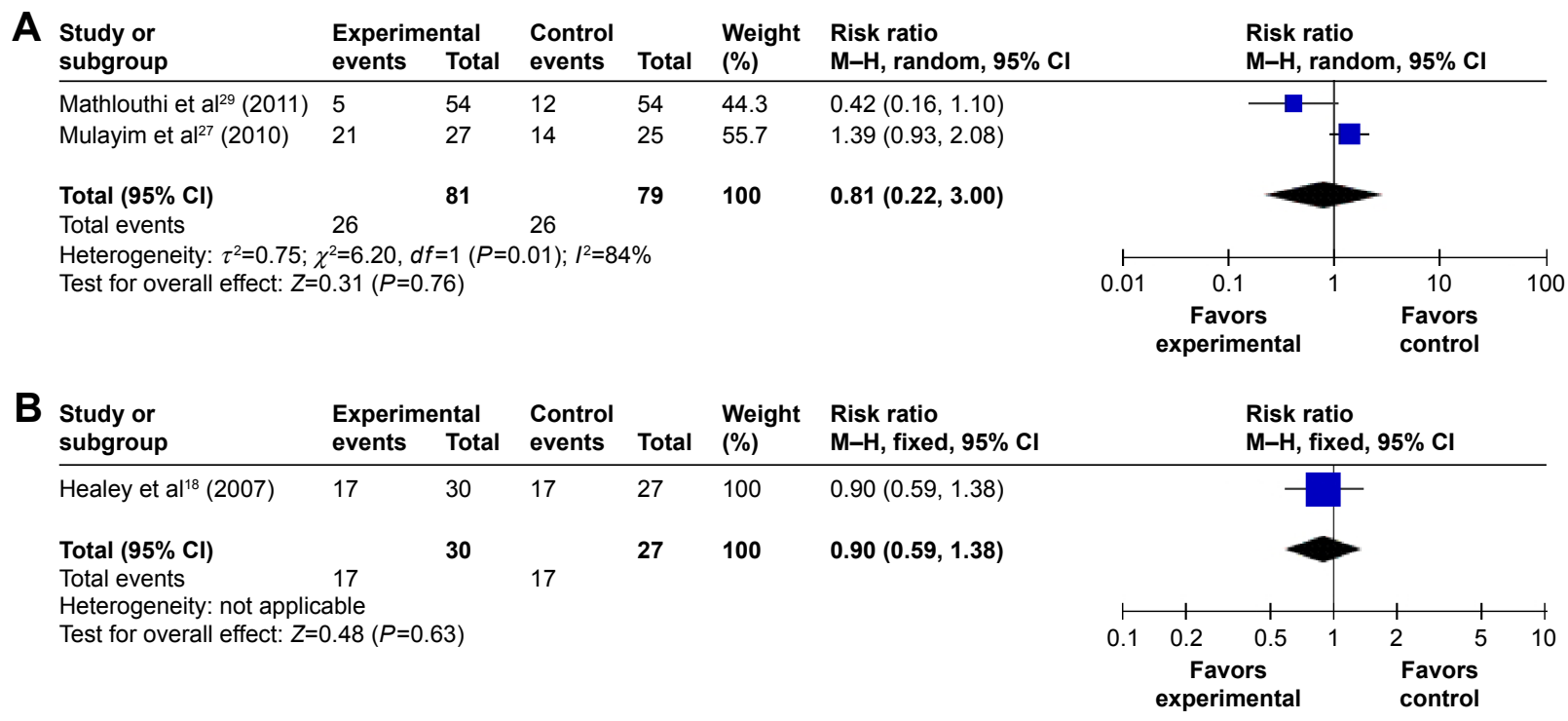

Figure 4 Comparison of the need for cervical dilatation between the misoprostol group and the placebo or no medication group.

Notes: (A) Sublingual misoprostol administration. (B) Oral misoprostol administration.

Abbreviations: $\mathrm{Cl}$, confidence interval; $d f$, degrees of freedom; $\mathrm{M}-\mathrm{H}$, Mantel-Haenszel. 


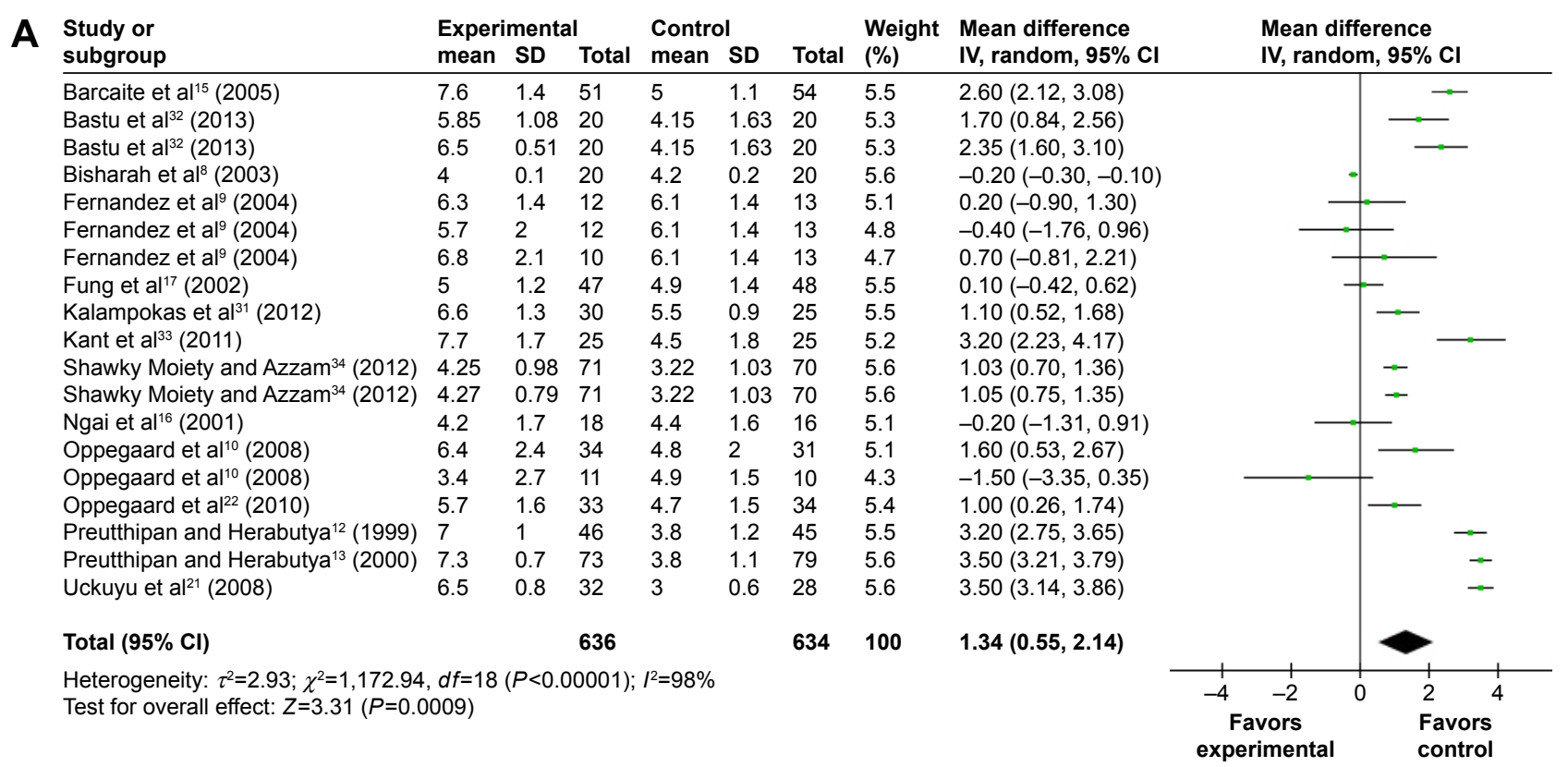

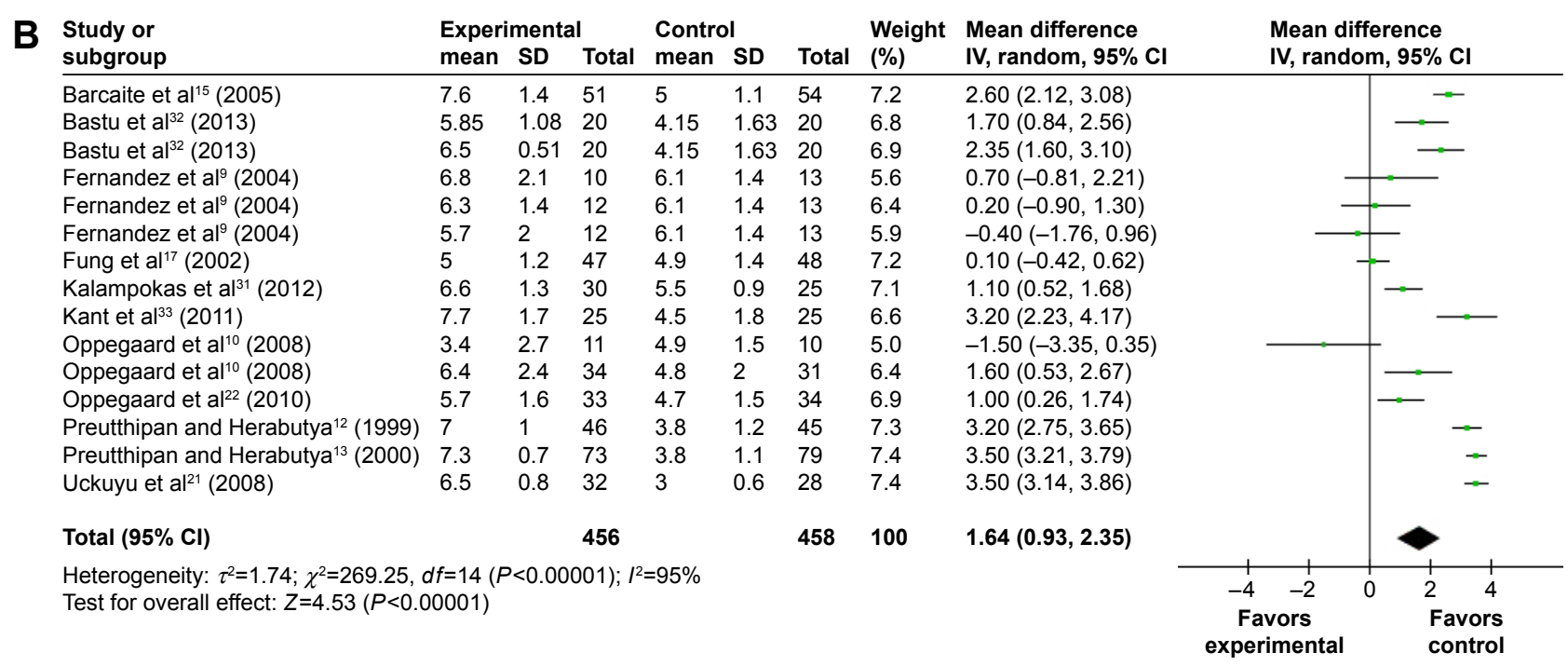

Figure 5 Comparison of the cervical width prior to hysteroscopy between the misoprostol group and the placebo or no medication group. Notes: (A) Irrespective of the route of misoprostol administration. (B) Vaginal misoprostol administration.

Abbreviations: $\mathrm{Cl}$, confidence interval; $\mathrm{df}$, degrees of freedom; IV, independent variable; SD, standard deviation.

The main outcome such as cervical width has a high degree of heterogeneity ( $I^{2}=98 \%$ Figure $5 \mathrm{~A}$ ) that could not be explained by either subgroup analysis or sensitivity analysis because of clinical diversity, including different populations under study, different regimens, doses, time intervals, and administration routes of misoprostol. However, when only patients pretreated with misoprostol vaginally were examined, the cervical width was significantly larger in the misoprostol group. Furthermore, the subgroup analysis indicated that the lower doses of 200 or $400 \mu \mathrm{g}$ vaginal misoprostol produced a more beneficial effect in the outcome of cervical width than the higher doses. Therefore, this statistical heterogeneity is mainly attributed to the different degree of beneficial effect of misoprostol on the final outcome, rather than the lack of effect of misoprostol in several of the trials.

Because the type of hysteroscopy is closely associated with the diameter of cervical dilatation, we conducted a subgroup analysis based on the type of hysteroscopy. When only diagnostic hysteroscopy was examined, there appeared to a lower need for cervical dilation, but this did not reach statistical significance. However, it appeared that females receiving misoprostol prior to operative hysteroscopy were more likely to avoid the need for cervical dilation. 


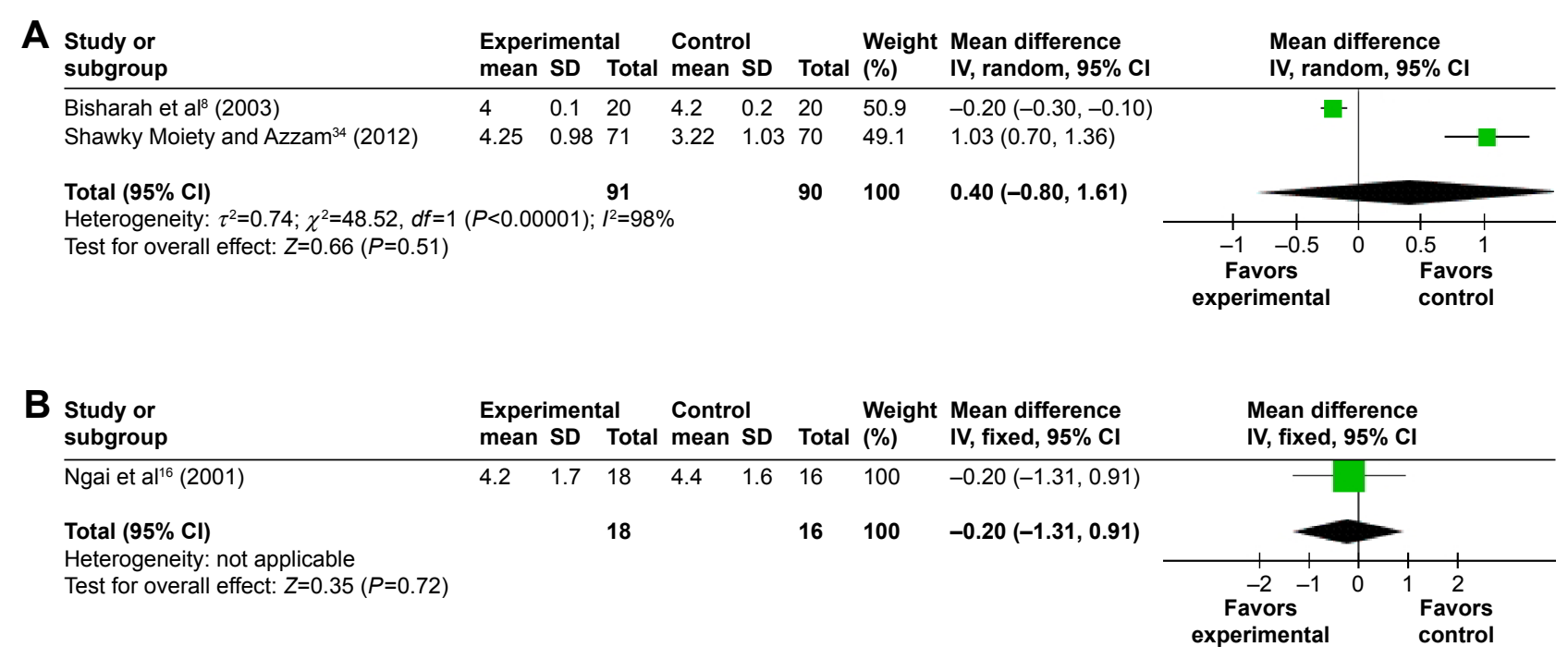

Figure 6 Comparison of the cervical width prior to hysteroscopy between the misoprostol group and the placebo or no medication group.

Notes: (A) Sublingual misoprostol administration. (B) Oral misoprostol administration.

Abbreviations: $\mathrm{Cl}$, confidence interval; $d f$, degrees of freedom; IV, independent variable; SD, standard deviation.

Thus, misoprostol appears to be more beneficial for operative hysteroscopy.

The route of misoprostol administration for cervical dilatation can be oral, vaginal, or sublingual. Among the three routes, vaginal administration has higher bioavailability, ${ }^{35}$ less severe gastrointestinal side effects, and longer sustained effect. ${ }^{36}$ Batukan et al found that vaginal administration was more effective than the oral route for preoperative cervical ripening, ${ }^{37}$ while other studies found no difference between the two routes, ${ }^{38}$ or among the three routes. ${ }^{39}$ In the present study, compared with the placebo or no medication group, the need for cervical dilatation, the mean cervical width,

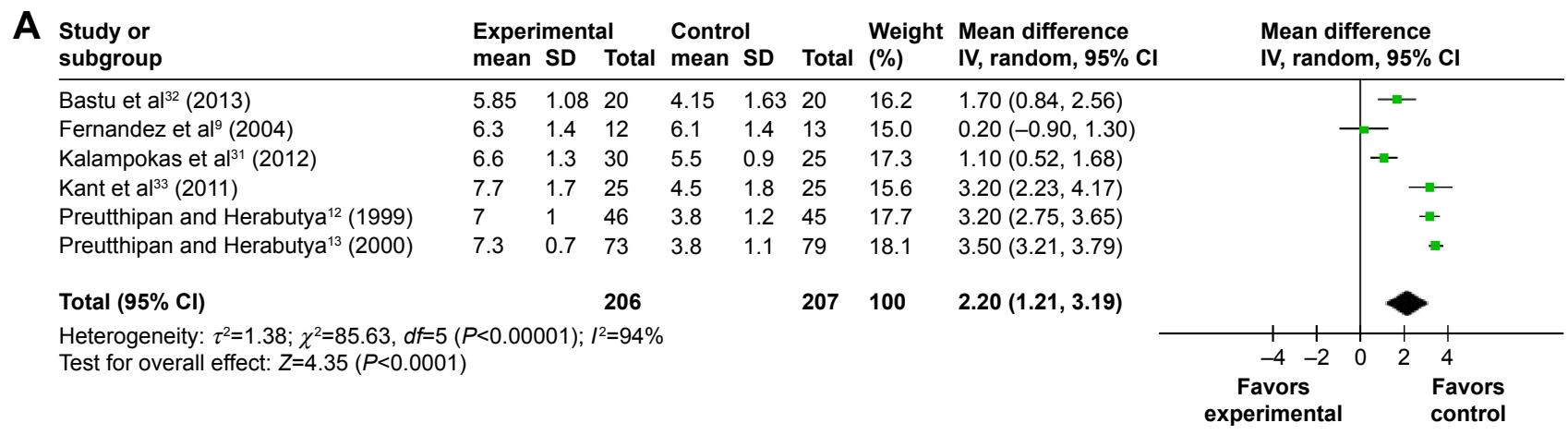

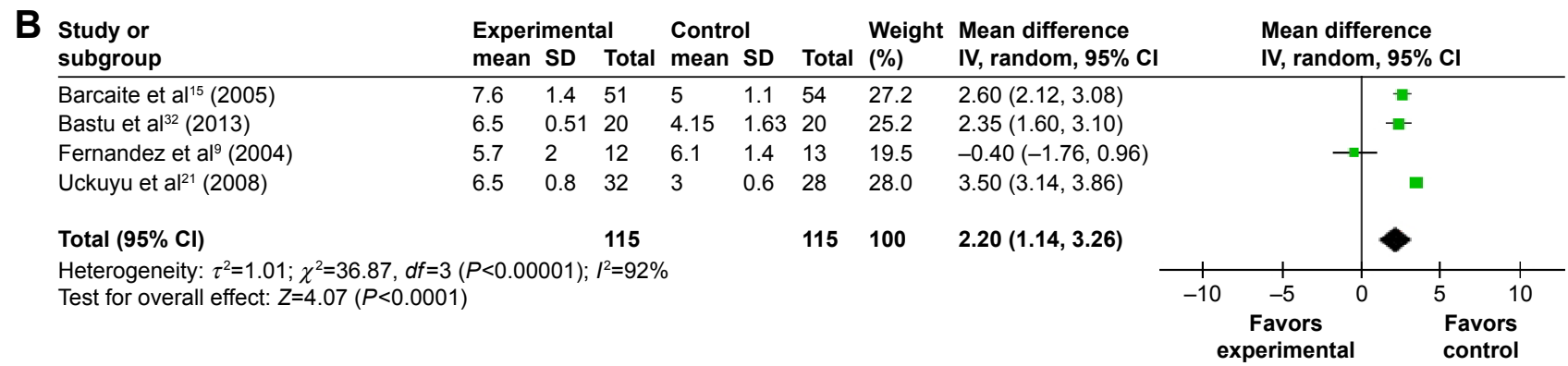

Figure 7 Comparison of the cervical width prior to hysteroscopy between the misoprostol group and the placebo or no medication group.

Notes: Vaginal administration of misoprostol (A) $200 \mu \mathrm{g}$ and (B) $400 \mu \mathrm{g}$.

Abbreviations: $\mathrm{Cl}$, confidence interval; $\mathrm{df}$, degrees of freedom; IV, independent variable; SD, standard deviation. 


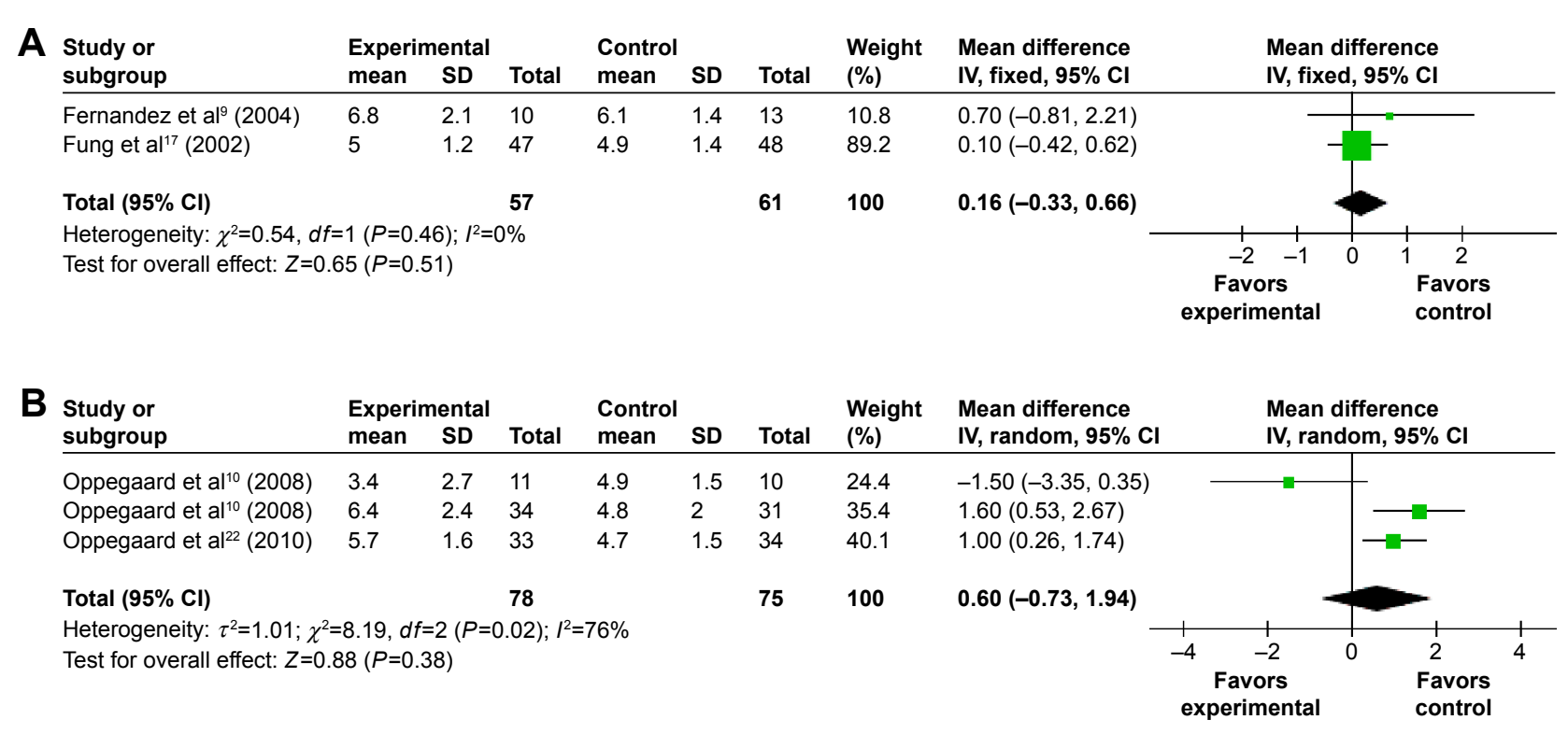

Figure 8 Comparison of the cervical width prior to hysteroscopy between the misoprostol group and the placebo or no medication group.

Notes: Vaginal misoprostol administration (A) $800 \mu \mathrm{g}$ and (B) I,000 $\mu \mathrm{g}$.

Abbreviations: $\mathrm{Cl}$, confidence interval; $d f$, degrees of freedom; IV, independent variable; SD, standard deviation.

and hysteroscopy complications (cervical laceration and false passage) after vaginal misoprostol administration reached statistical significance, but they did not after sublingual and oral misoprostol administration. Therefore, the vaginal route appeared to be superior to the oral or sublingual routes.

To determine the optimal doses of vaginal misoprostol administration, we performed another subgroup analysis. Compared with the placebo or no medication group, the mean cervical width after vaginal misoprostol administration was significantly greater in the 200 and $400 \mu \mathrm{g}$ subgroups, while in the 800 and $1,000 \mu \mathrm{g}$ subgroups, the mean cervical width was not significantly different. Therefore, 200 or $400 \mu \mathrm{g}$ of vaginal misoprostol prior to hysteroscopy is the optimal regimen.
It should be pointed out that all the misoprostol side effects such as diarrhea, fever, nausea, mild abdominal pain, and bleeding are significantly increased after the use of misoprostol. However, these side effects are generally minor, transient, and well tolerated by patients. Misoprostol side effects are related to dosage, interval, and route of administration. Increasing the dose and interval of vaginal misoprostol does not improve the effect on cervical dilatation but does increase the side effects. ${ }^{28}$ In addition, misoprostol, when administered vaginally, has fewer side effects compared with oral or sublingual administration. ${ }^{15,38,40}$

Compared with the meta-analysis by Polyzos et $\mathrm{al}^{41}$ and Gkrozou et $\mathrm{al}^{42}$ our meta-analysis identified 25 eligible

Table 2 Effect estimates on complications of hysteroscopy and side effects of misoprostol

\begin{tabular}{|c|c|c|c|}
\hline Complication & $\begin{array}{l}\text { Studies (number } \\
\text { of participants) }\end{array}$ & $\begin{array}{l}\text { Relative risk or mean } \\
\text { difference }(95 \% \mathrm{Cl})\end{array}$ & $P$-value \\
\hline I.I Cervical tear & $14(1,358)$ & $0.46(0.30,0.73)$ & 0.0008 \\
\hline I.2 Uterine perforation & $9(885)$ & $0.67(0.29,1.53)$ & 0.34 \\
\hline I.3 False passage & $7(628)$ & $0.33(0.15,0.74)$ & 0.007 \\
\hline 2.I Mild abdominal pain & $14(I, 423)$ & $5.49(3.76,8.00)$ & $<0.0000$ I \\
\hline 2.2 Bleeding & II $(I, 150)$ & $6.97(3.95,12.29)$ & $<0.00001$ \\
\hline 2.3 Nausea & $12(1,164)$ & $2.26(I .42,3.6 I)$ & 0.0006 \\
\hline 2.4 Diarrhea & II $(I, 256)$ & $6.53(3.23,13.22)$ & $<0.00001$ \\
\hline 2.5 Fever & 7 (786) & $6.36(2.23,18.13)$ & 0.0005 \\
\hline
\end{tabular}

Note: I, complications of hysteroscopy; 2, side effects of misoprostol.

Abbreviation: $\mathrm{Cl}$, confidence interval. 


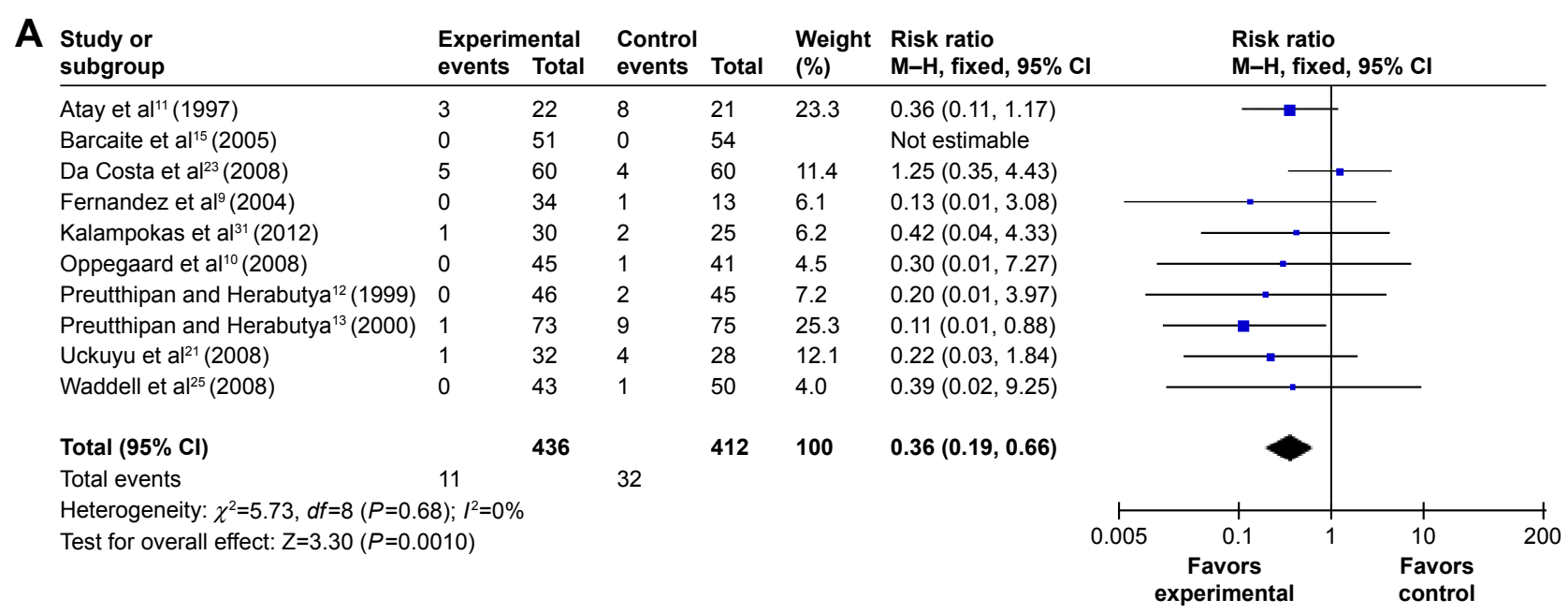

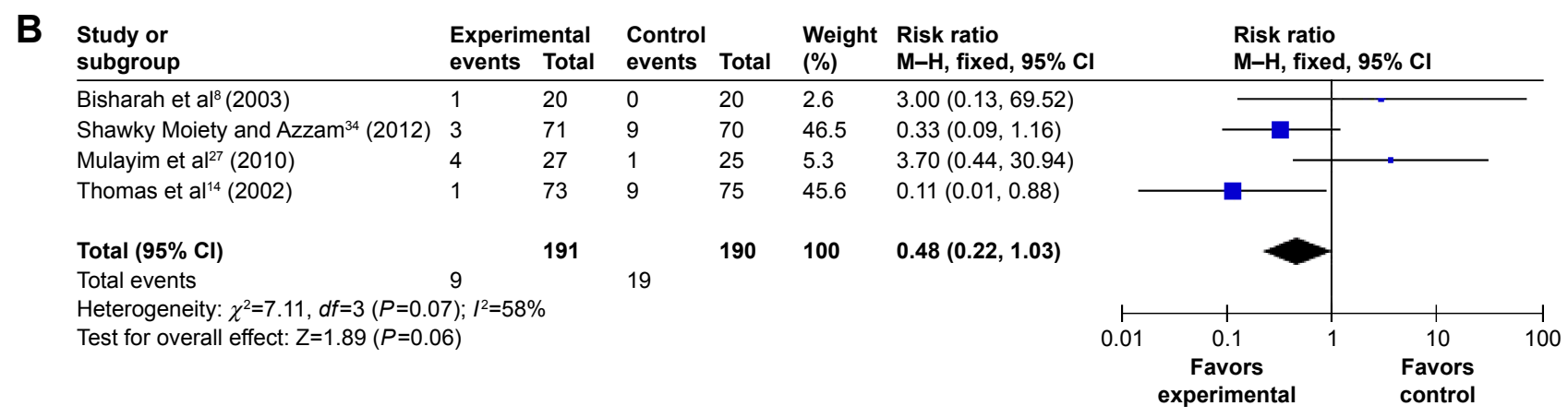

Figure 9 The complication of hysteroscopy: cervical laceration in the misoprostol group compared to the placebo or no medication group.

Notes: (A) Vaginal misoprostol administration. (B) Sublingual and oral misoprostol administration.

Abbreviations: $\mathrm{Cl}$, confidence interval; $d f$, degrees of freedom; $\mathrm{M}-\mathrm{H}$, Mantel-Haenszel.

studies that included more RCT studies. They had different emphasis such as menopausal status. Polyzos et al concluded that misoprostol may have a role as a cervical-ripening agent prior to hysteroscopy, and the efficacy of misoprostol is related to the menopausal status of patients. ${ }^{41}$ Whereas our meta-analysis shows that the efficacy of misoprostol is related to the type of hysteroscopy and route of administration. Although Gkrozou et al concluded that neither the need for cervical dilatation nor the complication of hysteroscopy was different between the misoprostol group and the placebo group..$^{42}$ Our meta-analysis shows that females may experience substantial benefits after pretreatment with misoprostol, especially prior to operative hysteroscopy and vaginal administration.

However, it is a fact that, although there have been 25 RCTs published to date, the heterogeneity among the regimens, doses, time intervals, and route of administration makes analysis of the data very difficult. Ultimately, it prevented us from providing a solid guideline regarding the optimal schedule of misoprostol administration, especially in patients who differ in terms of parity (nulliparous or parous), means of delivery (vaginal delivery or cesarean section), and estrogen status (pre- or postmenopausal period). Future RCTs covering more study subjects from carefully selected populations and a uniform administration route and dosage schedule of misoprostol should be performed to identify the ideal conditions for the use of misoprostol prior to hysteroscopy.

\section{Conclusion}

The use of misoprostol prior to hysteroscopy may facilitate cervical dilatation and decrease hysteroscopy complications (cervical laceration and false passage). On the other hand, the side effects of misoprostol were relatively mild and insignificant. Our meta-analysis recommends for obstetricians and therapists that the regimen of 200 or $400 \mu \mathrm{g}$ vaginal misoprostol may be optimal, especially prior to operative hysteroscopy. 


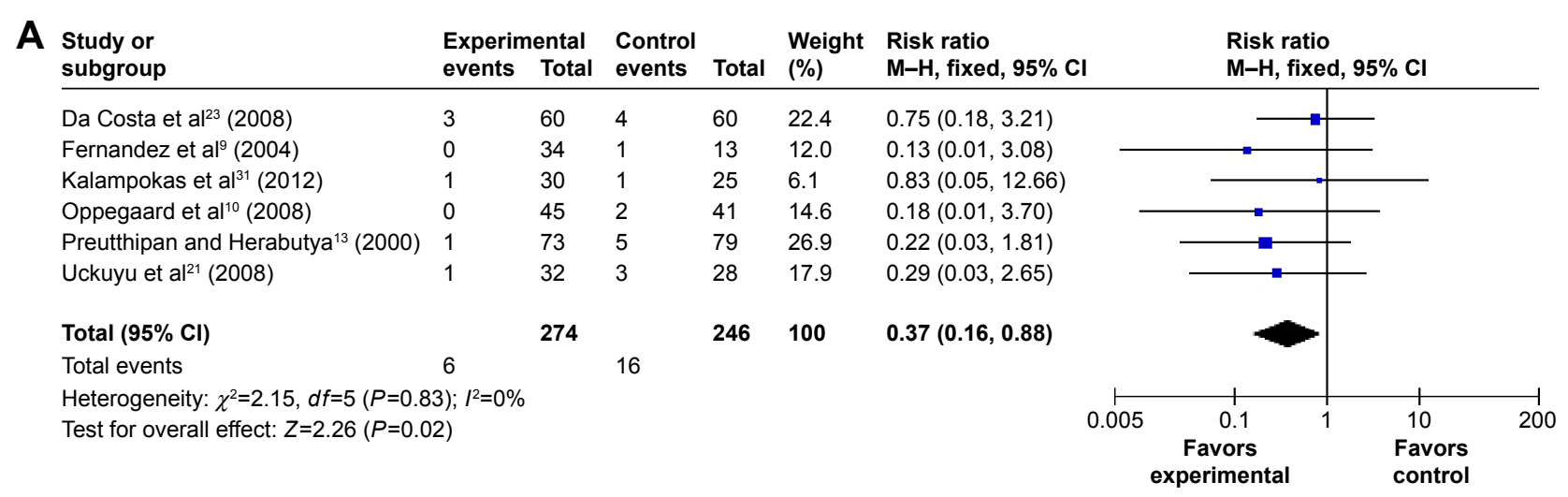

\begin{tabular}{|c|c|c|c|c|c|c|c|c|c|c|}
\hline \multirow{2}{*}{$\begin{array}{l}\begin{array}{l}\text { Study or } \\
\text { subgroup }\end{array} \\
\text { Mathlouthi et } \mathrm{al}^{29} \text { (2011) }\end{array}$} & \multicolumn{2}{|c|}{$\begin{array}{l}\text { Experimental } \\
\text { events Total }\end{array}$} & \multirow{2}{*}{$\begin{array}{l}\begin{array}{l}\text { Control } \\
\text { events }\end{array} \\
5\end{array}$} & \multirow{2}{*}{$\begin{array}{l}\text { Total } \\
54\end{array}$} & \multirow{2}{*}{$\begin{array}{l}\text { Weight } \\
\text { (\%) }\end{array}$} & $\begin{array}{l}\text { Risk ratio } \\
\mathrm{M}-\mathrm{H} \text {, fixed, } 95 \% \mathrm{Cl}\end{array}$ & \multicolumn{3}{|c|}{$\begin{array}{l}\text { Risk ratio } \\
\mathrm{M}-\mathrm{H} \text {, fixed, } 95 \% \mathrm{Cl}\end{array}$} & \\
\hline & 1 & 54 & & & & $0.20(0.02,1.66)$ & & - & & \\
\hline Total $(95 \% \mathrm{Cl})$ & & 54 & & 54 & 100 & $0.20(0.02,1.66)$ & & & & \\
\hline Total events & 1 & & 5 & & & & & & & \\
\hline Heterogeneity: not applicable & & & & & & $\longmapsto$ & & & 1 & \\
\hline Test for overall effect: $Z=1.49(P=0.14)$ & & & & & & 0.01 & $\begin{array}{c}0.1 \\
\text { Favors } \\
\text { experimental }\end{array}$ & 1 & $\begin{array}{c}10 \\
\text { Favors } \\
\text { control }\end{array}$ & 100 \\
\hline
\end{tabular}

Figure 10 The complication of hysteroscopy: false passage in the misoprostol group compared to the placebo or no medication group.

Notes: (A) Vaginal misoprostol administration. (B) Sublingual and oral misoprostol administration.

Abbreviations: $\mathrm{Cl}$, confidence interval; $d f$, degrees of freedom; $\mathrm{M}-\mathrm{H}$, Mantel-Haenszel.

\section{Acknowledgments}

This work was sponsored by the Zhejiang Provincial Program for the Cultivation of High-Level Innovative Health Talents. The study sponsors had no involvement in the collection, analysis, and interpretation of data, or in the writing of the manuscript.

\section{Disclosure}

The authors report no conflicts of interest in this work.

\section{References}

1. Birinyi L, Daragó P, Török P, et al. Predictive value of hysteroscopic examination in intrauterine abnormalities. Eur J Obstet Gynecol Reprod Biol. 2004;115(1):75-79.

2. Wortman M, Daggett A, Ball C. Operative hysteroscopy in an officebased surgical setting: review of patient safety and satisfaction in 414 cases. J Minim Invasive Gynecol. 2013;20(1):56-63.

3. Valle RF, Sciarra JJ. Current status of hysteroscopy in gynecologic practice. Fertil Steril. 1979;32(6):619-632.

4. Bradley LD. Complications in hysteroscopy: prevention, treatment and legal risk. Curr Opin Obstet Gynecol. 2002;14(4):409-415.

5. Lin CJ, Chien SC, Chen CP. The use of misoprostol in termination of second-trimester pregnancy. Taiwan J Obstet Gynecol. 2011;50(3): 275-282.

6. Thaisomboon A, Russameecharoen K, Wanitpongpan P, Phattanachindakun B, Changnoi A. Comparison of the efficacy and safety of titrated oral misoprostol and a conventional oral regimen for cervical ripening and labor induction. Int J Gynaecol Obstet. 2012;116(1): $13-16$.
7. Blanchard K, Clark S, Winikoff B, Gaines G, Kabani G, Shannon C. Misoprostol for women's health: a review. Obstet Gynecol. 2002;99(2): 316-332.

8. Bisharah M, Al-Fozan H, Tulandi T. A randomized trial of sublingual misoprostol for cervical priming before hysteroscopy. J Am Assoc Gynecol Laparosc. 2003;10(3):390-391.

9. Fernandez H, Alby JD, Tournoux C, et al. Vaginal misoprostol for cervical ripening before operative hysteroscopy in pre-menopausal women: a double-blind, placebo-controlled trial with three dose regimens. Hum Reprod. 2004;19(7):1618-1621.

10. Oppegaard KS, Nesheim BI, Istre O, Qvigstad E. Comparison of selfadministered vaginal misoprostol versus placebo for cervical ripening prior to operative hysteroscopy using a sequential trial design. BJOG. 2008;115(5):663, e1-e9.

11. Atay V, Duru NK, Pabuccu R, Ergün A, Tokac G, Aydin BA. Vaginal misoprostol for cervical dilatation before operative office hysteroscopy. Gynaecol Endosc. 1997;6(1):47-49.

12. Preutthipan S, Herabutya Y. A randomized controlled trial of vaginal misoprostol for cervical priming before hysteroscopy. Obstet Gynecol. 1999;94(3):427-430.

13. Preutthipan S, Herabutya Y. Vaginal misoprostol for cervical priming before operative hysteroscopy: a randomized controlled trial. Obstet Gynecol. 2000;96(6):890-894.

14. Thomas JA, Leyland N, Durand N, Windrim RC. The use of oral misoprostol as a cervical ripening agent in operative hysteroscopy: a double-blind, placebo-controlled trial. Am J Obstet Gynecol. 2002; 186(5):876-879.

15. Barcaite E, Bartusevicius A, Railaite DR, Nadisauskiene R. Vaginal misoprostol for cervical priming before hysteroscopy in perimenopausal and postmenopausal women. Int J Gynaecol Obstet. 2005;91(2): 141-145.

16. Ngai SW, Chan YM, Ho PC. The use of misoprostol prior to hysteroscopy in postmenopausal women. Hum Reprod. 2001;16(7): $1486-1488$ 
17. Fung TM, Lam MH, Wong SF, Ho LC. A randomized placebo-controlled trial of vaginal misoprostol for cervical priming before hysteroscopy in postmenopausal women. BJOG. 2002;109(5):561-565.

18. Healey S, Butler B, Kum FN, Dunne J, Hutchens D, Crane JM. A randomized trial of oral misoprostol in premenopausal women before hysteroscopy. J Obstet Gynaecol Can. 2007;29(8):648-652.

19. Higgins JPT, Douglas GA. Assessing risk of bias in included studies. In: Higgins JPT, Sally G, editors. Cochrane Handbook for Systematic Reviews of Interventions. Chichester: John Wiley \& Sons Ltd; 2008: $188-235$.

20. Higgins JP, Thompson SG. Quantifying heterogeneity in a metaanalysis. Stat Med. 2002;21(11):1539-1558.

21. Uckuyu A, Ozcimen EE, Sevinc FC, Zeyneloglu HB. Efficacy of vaginal misoprostol before hysteroscopy for cervical priming in patients who have undergone cesarean section and no vaginal deliveries. J Minim Invasive Gynecol. 2008;15(4):472-475.

22. Oppegaard KS, Lieng M, Berg A, Istre O, Qvigstad E, Nesheim BI A combination of misoprostol and estradiol for preoperative cervical ripening in postmenopausal women: a randomized controlled trial BJOG. 2010;117(1):53-61.

23. Da Costa AR, Pinto-Neto AM, Amorim M, Paiva LH, Scavuzzi A, Schettini J. Use of misoprostol prior to hysteroscopy in postmenopausal women: a randomized, placebo-controlled clinical trial. J Minim Invasive Gynecol. 2008;15(1):67-73.

24. Valente EP, de Amorim MM, Costa AA, de Miranda DV. Vaginal misoprostol prior to diagnostic hysteroscopy in patients of reproductive age: a randomized clinical trial. J Minim Invasive Gynecol. 2008; $15(4): 452-458$.

25. Waddell G, Desindes S, Takser L, Beauchemin MC, Bessette P. Cervical ripening using vaginal misoprostol before hysteroscopy: a double-blind randomized trial. J Minim Invasive Gynecol. 2008;15(6):739-744.

26. Singh N, Ghosh B, Naha M, Mittal S. Vaginal misoprostol for cervical priming prior to diagnostic hysteroscopy - efficacy, safety and patient satisfaction: a randomized controlled trial. Arch Gynecol Obstet. 2009;279(1):37-40.

27. Mulayim B, Celik NY, Onalan G, Bagis T, Zeyneloglu HB. Sublingual misoprostol for cervical ripening before diagnostic hysteroscopy in premenopausal women: a randomized, double blind, placebo-controlled trial. Fertil Steril. 2010;93(7):2400-2404.

28. El-Mazny A, Abou-Salem N. A double-blind randomized controlled trial of vaginal misoprostol for cervical priming before outpatient hysteroscopy. Fertil Steril. 2011;96(4):962-965.

29. Mathlouthi N, Saodi O, Ben Temime R, Makhlouf T, Attia L, Chachia A. Sublingual misoprostol for cervical ripening before diagnostic hysteroscopy: a randomized and prospective study about 108 cases. Tunis Med. 2011;89(11):825-829.
30. Sordia-Hernández LH, Rosales-Tristan E, Vazquez-Mendez J, et al. Effectiveness of misoprostol for office hysteroscopy without anesthesia in infertile patients. Fertil Steril. 2011;95(2):759-761.

31. Kalampokas E, Sofoudis C, Antonogeorgos G, et al. A randomized controlled trial for cervical priming using vaginal misoprostol prior to hysteroscopy in women who have only undergone cesarean section. Arch Gynecol Obstet. 2012;286(4):853-857.

32. Bastu E, Celik C, Nehir A, Dogan M, Yuksel B, Ergun B. Cervical priming before diagnostic operative hysteroscopy in infertile women: a randomized, double-blind, controlled comparison of 2 vaginal misoprostol doses. Int Surg. 2013;98(2):140-144.

33. Kant A, Divyakumar, Priyambada U. A randomized trial of vaginal misoprostol for cervical priming before hysteroscopy in postmenopausal women. J Midlife Health. 2011;2(1):25-27.

34. Shawky Moiety FM, Azzam A. Prostaglandins prior to hysteroscopy. Gynecol Surg. 2012;9(1):169-173.

35. Tang OS, Gemzell-Danielsson K, Ho PC. Misoprostol: pharmacokinetic profiles, effects on the uterus and side-effects. Int J Gynaecol Obstet. 2007;99(2):S160-S167.

36. Tang OS, Schweer H, Seyberth HW, Lee SW, Ho PC. Pharmacokinetics of different routes of administration of misoprostol. Hum Reprod. 2002;17(2):332-336.

37. Batukan C, Ozgun MT, Ozcelik B, Aygen E, Sahin Y, Turkyilmaz C. Cervical ripening before operative hysteroscopy in premenopausal women: a randomized, double-blind, placebo-controlled comparison of vaginal and oral misoprostol. Fertil Steril. 2008;89(4):966-973.

38. Choksuchat C, Cheewadhanaraks S, Getpook C, Wootipoom V, Dhanavoravibul K. Misoprostol for cervical ripening in non-pregnant women: a randomized double-blind controlled trial of oral versus vaginal regimens. Hum Reprod. 2006;21(8):2167-2170.

39. Lee YY, Kim TJ, Kang H, et al. The use of misoprostol before hysteroscopic surgery in non-pregnant premenopausal women: a randomized comparison of sublingual, oral and vaginal administrations. Hum Reprod. 2010;25(8):1942-1948.

40. Tanha FD, Salimi S, Ghajarzadeh M. Sublingual versus vaginal misoprostol for cervical ripening before hysteroscopy: a randomized clinical trial. Arch Gynecol Obstet. 2013;287(5):937-940.

41. Polyzos NP, Zavos A, Valachis A, et al. Misoprostol prior to hysteroscopy in premenopausal and post-menopausal women. A systematic review and meta-analysis. Hum Reprod Update. 2012;18(4):393-404.

42. Gkrozou F, Koliopoulos G, Vrekoussis T, et al. A systematic review and meta-analysis of randomized studies comparing misoprostol versus placebo for cervical ripening prior to hysteroscopy. Eur J Obstet Gynecol Reprod Biol. 2011;158(1):17-23.
Drug Design, Development and Therapy

\section{Publish your work in this journal}

Drug Design, Development and Therapy is an international, peerreviewed open-access journal that spans the spectrum of drug design and development through to clinical applications. Clinical outcomes, patient safety, and programs for the development and effective, safe, and sustained use of medicines are the features of the journal, which

\section{Dovepress}

has also been accepted for indexing on PubMed Central. The manuscript management system is completely online and includes a very quick and fair peer-review system, which is all easy to use. Visit http://www.dovepress.com/testimonials.php to read real quotes from published authors. 